\title{
Em busca de narrativas densas: questões acerca de realidades narrativas, subjetividade e agência social
}

\author{
Anna Catarina Morawska-Vianna
}

\begin{abstract}
resumo Tendo como pano de fundo a experiência de trabalho de campo no bairro de Peixinhos em Olinda, o presente artigo busca levantar algumas questôes relacionadas à importância de se considerar narrativas cotidianas, de passado e identitárias, assim como as realidades por elas construídas nas análises antropológicas. $\mathrm{O}$ trabalho discute a abordagem do psicólogo Jerome Bruner em torno do que ele chama de "realidades narrativas", seus diálogos implícitos com a antropologia, como com o conceito de cultura geertziano e com as discussôes atuais na disciplina sobre a análise de processos de subjetivação. A idéia é pensar criticamente o alcance e limites da teoria de cultura de Clifford Geertz e apontar como alternativa alguns dos conceitos de Homi Bhabha acerca da agência social, da subjetividade e do pertencimento cultural a partir de um olhar atento a dinâmicas sociais e políticas que influenciam e definem grupos enquanto tais.
\end{abstract}

palavras-chave Realidades narrativas. Antropologia da subjetividade. Agência social. Jerome Bruner.

Dizem que o bairro de Peixinhos começou como um engenho no século XVII, mas o que vive mesmo na memória de seus moradores é o antigo matadouro. A construção, que antes era o coração do bairro e o sustento da maioria das famílias, continua lá, enorme, com uma parte recém-reformada, palco de disputas políticas, e outra apodrecendo com a ação do tempo, do lixo, dos ratos e urubus. Assim como o rio que dá nome ao bairro. Divisa de Olinda e Recife, o que antes era um rio cheio de peixinhos, hoje, diz Zuleide, jaz em lama podre e de cheiro inconfundível, onde nem os urubus querem pousar, onde se joga adolescentes assassinados chamando-os de presuntos, onde o lixo exala a situação do povo. (Paula, 1999, p. 15)

Lugar antes considerado "terra de índio" segundo dona Ester, "terra de homens valentes de peixeira na cinta", hoje uma das regióes mais violentas de Olinda, Peixinhos gerou e ainda gera grandes movimentos sociais, e pessoais (por que náo?), dos quais seus moradores se orgulham, e de cujas memórias compartilham.

Um desses movimentos pessoais vitoriosos foi o de Zuleide de Paula, que em 1999 teve um livro publicado - uma de suas "realizaçóes mais profundas" (p. 11) - reunindo memórias suas e de outros moradores do bairro, sobre estórias do passado, da infância, das antigas manifestaçôes culturais de rua, dos cultos religiosos, das mobilizaçôes em nome de reivindicaçóes políticas e da sua organização em torno de creches, clubes e centros culturais.

As memórias no livro vão se tecendo quase com vida própria: os edifícios se ligam aos personagens, um a um tomando forma. Entre elas está a memória do já mencionado Matadouro, inaugurado em 1919 e por muito tempo o centro da vida dos moradores de Peixinhos. Apesar de fechado em 1970, sua constante presença e visibilidade o mantiveram como um espaço liminar, não apenas pelas figuras que lá passaram a freqüentar, como os meninos "cheira-cola", mas também por carregar a memória dos velhos da comunidade. A cada olhar para o prédio, os fantasmas do passado se erguem para aqueles que entáo viveram a sua época áurea. 
I 54 | Anna Catarina Morawska-Vianna

Num livro verdadeiramente dialogado e dialógico em termos bakhtinianos, Zuleide dá voz aos velhos - Maria Gadelha, senhor Biu da Procissão, dona Duda, dona Ester, seu Efigênio, senhor Caetano, Oriosvaldo e muitos outros - e faz do leitor um interlocutor de uma conversa informal:

O nome da rua da Harmonia foi trocado para Terezita Bandeira. Quem trocou? Quem é ou foi Terezita Bandeira? Você sabe? Nem eu. (Paula, 1999, p. 15)

A marca dialógica, em que múltiplas vozes da memória discursiva de uma formação social se mostram em sua heterogeneidade (Fiorin, 2004), emerge a partir do seu tom de denúncia em relaçáo à violência e ao descaso público: como muitas das mulheres no bairro, Zuleide sofreu a perda de um filho, "vítima do descaso da saúde pública em nosso Estado para com os que náo têm alto poder aquisitivo" (Paula, 1999, p. 11). A dialogia também emerge nas diversas referências às mobilizaçôes dos moradores:

Da próxima vez que o povo for considerado como verme, entre na luta também, pois lembre-se que cruzar os braços náo leva a nada. (Paula, 1999, p. 102)

Uma dessas mobilizações foi a "luta contra o lixo" que durou quase um ano, de novembro de 1983 a setembro de 1984, iniciada quando descobriram que seria instalada no bairro uma estação de transbordo de lixo. Seu lema era: "Peixinhos não é penico". Depois de um primeiro ato público, a Prefeitura concordou em dialogar com os moradores, e, para convencê-los a consentir com a obra, exigência dos financiadores internacionais, passou a mandar técnicos para reuniōes semanais no bairro, chegando até mesmo a pagar uma viagem a São Paulo e Rio de Janeiro para que uma comissão de moradores visse o quão "seguro" era o funcionamento deste tipo de instalação. Depois de um empate na comissão, os moradores decidiram que náo assinariam o documento dando seu consentimento para a Prefeitura efetuar a obra. Como esta resolveu ignorar a decisão dos moradores, mais atos públicos, reuniōes e debates nas ruas e esquinas, passeatas, peças de teatro, shows, palestras:

No dia 20 de agosto saiu no Diário Oficial que Peixinhos não seria depósito de lixo. (...) Em 21 de setembro de 1984, às 20 horas, no pátio da feira, houve a grande festa da vitória. Comemoramos com shows, poesias, repentistas, ciranda, o bloco da cobra e muito mais. (Paula, 1999, p. 101)

Entre as narrativas de mobilização, a luta contra o lixo se tornou recorrente. Tanto assim que um recente movimento musical no bairro, iniciado em 1995, foi batizado de Boca do Lixo, trazendo à memória a luta coletiva, como se quisesse marcar a resistência como espécie de vocação da comunidade. Os jovens do Boca do Lixo foram inicialmente impulsionados pelo espaço que o movimento Mangue Beat de Chico Science e Nação Zumbi havia conseguido na mídia, e como dois dos músicos do Nação Zumbi eram originários do bairro, descobria-se ali outra vocação: a vocação para a cultura. À medida que o Mangue Beat toma envergadura nacional, o movimento Boca do Lixo se afirma enquanto expressão cultural local.

Protagonistas de narrativas de passado e memória, o Matadouro, a luta contra o lixo e o movimento Boca do Lixo reinscrevem o passado, reativam, reposicionam, resignificam-no. Essa habilidade, de acordo com Homi Bhabha: 
(...) compromete nosso entendimento do passado e nossa reinterpretação do futuro a uma ética de 'sobrevivência' que nos permite agir através do presente (1998, p. 35, traduçáo minha, grifo no original).

$\mathrm{O}$ resgate, a construção e a manutenção desta memória, conjugados ao uso da linguagem do pertencimento comunitário e cultural, é justamente o que possibilita a inserção dos moradores em dinâmicas sociais e políticas em que reivindicam reconhecimento:

é uma exigência feita em nome de um povo cujas experiências históricas fizeram, em geral, com que vivesse os valores da 'pessoalidade' como uma experiência social, coletiva - a 'comunidade' se torna o local da agência social (Bennet; Bhabha, 1998, p. 44-45, tradução minha).

As narrativas compartilhadas conferem a Zuleide e a muitos em Peixinhos a sensação de comunidade enquanto agente social, e são o tecido que reorganiza e tece por sua vez a ação sobre o presente, que imediatamente se torna uma nova narrativa - a da ação política de apropriação do antigo Matadouro. Agora Nascedouro, "nascedouro da cultura popular", como reza a poesia de Oriosvaldo de Almeida (Paula, 2001, p. 58), um dos poetas locais, os antigos prédios do Matadouro passaram a ser ocupados na segunda metade da década de 1990 pelos integrantes do Boca do Lixo e por grupos de danças populares e sendo usados como palco de shows e peças de teatro.

A luta pelo reconhecimento institucional por parte dos órgãos públicos rendeu frutos: o movimento conseguiu verbas públicas, municipal e estadual, para uma grande reforma em dois dos prédios, que não surpreendentemente andava a passos de tartaruga e foi acelerada ante a perspectiva de sua inauguração com a presen- ça de representantes do Poder Público em fim de mandato e às vésperas de eleiçóes. ${ }^{1}$

A confecção do livro de Zuleide se insere em um movimento mais amplo de preocupação em resgatar o passado e, dessa maneira, enquanto comunidade que compartilha narrativas de memória, atuar no jogo político do presente. Zuleide parece saber da agência social que a marca:

(...) uma das coisas que me objetivava era recordar os momentos que marcaram, o por quê e o para quê. Comecei a aprender a importância do por quê e para quê a partir de minha participação nas lutas e organizaçóes das comunidades, conhecendo pessoas, superando as frustraçôes, descobrindo valores que estavam adormecidos. (Paula, 1999, p. 9)

1. O presente artigo foi originalmente escrito em dezembro de 2005. A inauguraçáo oficial do Nascedouro se deu em 16 de março de 2006, com a presença dos três políticos com os cargos de maior expressão em Pernambuco: o governador do Estado, o prefeito de Recife e a prefeita de Olinda. Os três haviam contribuído para a reforma porque, apesar de o Nascedouro estar localizado em Recife, na fronteira com Olinda, seus portôes são virados para o bairro olindense de Peixinhos: foi sempre esta população que usufruiu de suas instalaçóes, seja como mão-de-obra no Matadouro, seja se apropriando de suas ruínas, seja utilizando as suas recém-inauguradas instalaçóes. Como 2006 foi ano eleitoral, a inauguraçáo do Nascedouro se mostrou importante pelos frutos políticos que tal empreendimento poderia render aos representantes municipais e estaduais. Um ano depois, em 10 de março de 2007, quando da viagem do presidente da Alemanha a Pernambuco, o "Centro Cultural e Desportivo Nascedouro de Peixinhos" foi incluído na agenda de visitas deste como um modelo de projeto de investimento social por parte do Poder Público. A comitiva alemã, o prefeito de Recife e o governador do Estado foram recebidos na ocasiáo com faixas de protesto em alemáo produzidas pelos moradores, insatisfeitos com as manobras políticas realizadas pelos representantes dos governos municipais e estadual para diminuir a participação da população do bairro na gestão do Centro Cultural. 
E não apenas ela. Nesse mesmo movimento do quase-grito de memória, quando se anda por Peixinhos e se conversa com seus moradores, jorram narrativas cotidianas, marcadas por episódios de nascimento e morte, violência e marginalidade, que pulsam como o extraordinário tornado ordinário; jorram também narrativas do passado, memórias alimentadas pelo presente; e jorram narrativas identitárias, parte do jogo político em que a regra é a da linguagem do pertencimento cultural.

A proposta do presente artigo é apresentar algumas reflexóes que emergiram a partir do meu contato com o livro de Zuleide e a partir das tais narrativas cotidianas, identitárias e de passado com que me deparei como antropóloga estudando uma organização não-governamental organizada por moradores do próprio bairro. ${ }^{2}$ Apesar de náo diretamente ligadas a meu tema de pesquisa, certas questốes a tangenciavam constantemente na minha experiência em campo: como levar a sério tais narrativas e incorporá-las em minha análise? Que tipos de conseqüências metodológicas e teóricas adviriam de tal postura? Como pensar uma certa agência social a partir da construção narrativa de uma comunidade, como nos sugere Homi Bhabha? Tendo o livro de Zuleide, o Matadouro, a luta contra o lixo e o movimento Boca do

2. Minha pesquisa propriamente dita estabelece como objetivo central elaborar uma etnografia que trace conexôes entre organizaçôes não governamentais (ONGs) em Recife e Olinda, especificamente as que atuam em torno da "área da infância e adolescência", e agências financiadoras internacionais. Parto da relação entre três ONGs em Recife e Olinda, cujos integrantes são moradores das próprias "comunidades" dentro das quais oferecem há cerca de 20 anos atividades extra-escolares para crianças e adolescentes (Galpão dos Meninos e Meninas de Santo Amaro, Recife; Grupo Sobe e Desce de Olinda; e Grupo Comunidade Assumindo suas Crianças, em Peixinhos, Olinda), e a agência financiadora católica inglesa, Catholic Agency for Overseas Development (CAFOD), que as financia desde sua origem.
Lixo em Peixinhos como pano de fundo, a discussão aqui colocada tem menos a pretensão de oferecer respostas definitivas, e mais de levantar questóes relacionadas à noção de realidades narrativas e à idéia da construção narrativa como elemento de mediaçấo entre subjetividade e cultura e como lócus de agência social.

Partindo dos escritos de Jerome Bruner, um psicólogo que colocou no cerne de suas reflexôes a discussão sobre realidades narrativas, a primeira questão abordada é a importância de se considerar a narrativa náo apenas como objeto de estudo, mas também instrumento de metacognição no fazer antropológico. Defendo a importância de uma reflexividade crítica em relaçáo às narrativas antropológicas, uma vez que estas não são exteriores ao mundo social sobre o qual discorrem, mas nele se inserem e nele provocam, muitas vezes, efeitos sociais que não podem ser desprezados nos estudos antropológicos.

Levar a sério a idéia de realidades narrativas incita reflexões metodológicas, como se verá na primeira parte, porém também teóricas, como será explorado em um segundo momento. $\mathrm{O}$ objetivo, na segunda parte, é o de apresentar os pressupostos da "psicologia cultural" que Jerome Bruner busca fundar, baseada no estudo da narrativa como mediadora de um mundo canônico cultural e um mundo idiossincrático. Apesar de tal discussão estar situada dentro de um contexto específico de discussão teórica, o da academia norte-americana, tal reflexão torna-se interessante para uma discussão antropológica mais abrangente por dois motivos. O primeiro é o fato das concepçôes de Bruner terem sido bastante influenciadas pela antropologia interpretativa de Clifford Geertz. A intenção aqui, no entanto, não é a de analisar minuciosamente o conceito de cultura semiótico de tal antropólogo, tampouco explorar seu uso de certa linha da filosofia da linguagem, mas simplesmente expor como esta psicologia cultural dialoga com o conceito de cultura geertziano. 
Em segundo lugar, tal discussão importa para a antropologia porque tangencia uma preocupação recente em pensar a subjetividade a partir de uma perspectiva antropológica.

Assim, na parte final, após discorrer acerca da tentativa de Bruner de analisar a relação entre mundo cultural e mundo idiossincrático através da narrativa, passo para a discussão empreendida pela antropóloga Sherry Ortner (2005), sobre um esforço que está sendo feito na antropologia atual para se pensar a configuração cultural da subjetividade. Apesar do tema não ser novo na disciplina, as formas de explorá-lo o são. Procuro sugerir algumas das idéias de Homi Bhabha como um possível caminho para essa linha de pesquisa.

\section{Seguindo narrativas: a sensibilidade metacognitiva no fazer antropológico}

Em um livro fenomenal escrito em 1954, o antropólogo Edmund Leach, com suas próprias rixas domésticas com o funcionalismo britânico, escrevia o quanto o antropólogo, em seu trabalho de campo, deparava-se não com sistemas lógicos passíveis de dedução através da observação participante, mas sim com um mar de incongruências e contradiçóes. Percebendo que as incongruências faziam parte de uma dinâmica política local por legitimidade e posiçôes sociais, uma das conclusões a que chega é a da necessidade de se levar a sério as ambigüidades, e não rejeitá-las como poluição para a sistematização dos dados. ${ }^{3}$

3. O autor tenta demonstrar como as versóes dos mitos para os Kachins são fundamentais e significativas para justificar posições sociais. As histórias que recontam, que elaboram sobre suas tradiçóes, servem para justificar querelas, legitimar costumes e acompanhar representações religiosas, não havendo, portanto, versôes autênticas. A divergência entre versóes se relaciona com o interesse dos indivíduos e com o status das linhagens (Leach, 1996 [1954]).
De fato, não há antropólogo que não tenha no cotidiano de seu campo a experiência da incongruência e ambigüidade, através de estórias narradas de diferentes maneiras, construçốes diversas de experiências comuns. Segundo Jerome Bruner (2001 [1996]), todos nós vivemos em um mar de estórias, e como os peixes, que são os últimos a enxergar a água, temos dificuldades em compreender o que significa estarmos mergulhados em estórias. Se as narrativas constroem realidades, e são estas realidades que buscamos enquanto acadêmicos, como se daria o esforço por uma antropologia que tentasse enxergá-las através deste mar de narrativas, tão onipresente e automático?

Para Bruner, haveria três antídotos clássicos contra a inconsciência do automático e do onipresente. Os dois primeiros são o contraste e a confrontação de versóes de realidades narrativas que colidem entre si. O terceiro é a metacognição, que transforma os argumentos ontológicos sobre o "ser", sobre a natureza da realidade, em argumentos epistemológicos sobre o "saber", sobre as maneiras como nós conhecemos. O objeto do pensamento é o pensamento em si, que nesse caso é dirigido aos códigos de linguagem que organizam e expressam os pensamentos. Se o contraste e confrontação nos alertam para a relatividade do saber, a metacognição possibilita uma postura aberta em relação às formas do saber e de elaboração da realidade, ou seja, das construçóes de diferentes ontologias.

Vivemos a maior parte de nossas vidas em um mundo construído de acordo com as regras e os recursos da narrativa. Voltar nossa atenção às narrativas é chave para compreender a(s) realidade(s) construída(s), realidades estas disputadas e compartilhadas, e as dinâmicas sociais em torno delas, em termos de conflitos e alianças. Mas não apenas. Como antropólogos, ao irmos a campo, vamos repletos de narrativas próprias e nos deparamos com mundos outros narrados. Em uma de suas análises do discurso narrativo, Bruner (1986) mostra como o modo 
paradigmático (lógico-científico) de pensamento, típico da ciência, compartilha a narratividade com o modo de pensamento narrativo propriamente dito. Tanto o modo de pensamento paradigmático (lógico-científico) quanto o narrativo se utilizam de certos elementos do texto literário que contribuem, segundo Bruner, para o que Wolfgang Iser, em uma obra chamada The Act of Reading, de 1978, inspirado por Barthes, chama de "subjuntivizar a realidade" (estar em modo subjuntivo), ou seja, se referir a possibilidades e não a certezas, tornando o mais aberto possível o significado do texto, compartilhando com o leitor a responsabilidade por sua interpretação. Ambos, portanto, o texto literário e o texto científico, utilizam-se em graus distintos de: a) ativação de pressupostos, isto é, criação de significados não explícitos, fazendo com que a liberdade interpretativa do leitor aumente; b) subjetivação, percepção das realidades não através de um olhar onisciente, mas através da consciência de protagonistas; e c) perspectivas múltiplas, como um conjunto de prismas (cf. Bruner, 1986).

Se ambos, o mundo social e o mundo científico-acadêmico, são marcados pela narratividade, devemos incorporar no nosso método científico uma constante sensibilidade metacognitiva, um perene esforço de ver como o "mar de estórias" em que o antropólogo está mergulhado se funde e se mostra presente no "mar de estórias" do mundo social dos sujeitos objeto de estudo. Narrativas antropológicas de "culturas", originalidades e passados tradicionais muitas vezes legitimam narrativas identitárias do mundo social enquanto linguagem política. O mundo da realidade narrativa de muitos dos grupos estudados na antropologia é hoje marcado pela narrativa historicamente consagrada da própria disciplina. E o mundo $\mathrm{da}$ realidade narrativa antropológica, com suas etnografias clássicas, descriçôes densas, análises funcionalistas, estruturalistas e pós-modernas, para citar apenas algumas, alimenta-se das realidades narrativas do mundo social, frequentemente "antropologizadas", por assim dizer, ou seja, que incorporam conceitos consagrados na disciplina como o de "cultura". ${ }^{4}$ A relação entre tais narrativas se dá como um ciclo virtuoso, como numa condiçáo de hibridez bhabhaniana, em que narrativas antropológicas e antropologizadas nunca simplesmente "são", mas estão sempre "sendo", continuamente em construção umas a partir das outras.

Em Peixinhos, o resgate de narrativas do passado se liga a reivindicaçóes políticas frente ao Poder Público que tomam a forma de afirmação de uma cultura comum. No Brasil, não só as demandas das populaçóes indígenas, mas também de comunidades remanescentes de quilombos estão na ordem do dia no que concerne ao resgate do passado e de uma genealogia comum que legitime reivindicaçôes legais. No mundo todo, é generalizado o uso da idéia

4. Penso aqui em situaçóes em que as narrativas antropológicas e os conceitos que estas carregam exercem certos efeitos sociais e se tornam relevantes em determinadas dinâmicas sociais, como, por exemplo, em situaçôes em que obras de Pierre Verger são usadas por grupos de terreiros como forma de aprenderem o conhecimento "puro" que possa legitimar sua prática. Para usar um exemplo mais clássico, basta lembrar de como o conceito de cultura boasiano foi fortemente usado por atores sociais, inclusive pelo próprio Boas, contrários ao racismo. É evidente que as narrativas antropológicas não formam um texto social coerente e sólido politicamente, como também é certo que nem todo texto acadêmico produz efeitos sociais. No entanto, Bourdieu (1984) nos lembra que as disciplinas não flutuam acima do mundo social, mas interagem com ela, e que, dependendo da posição do acadêmico no campo do qual faz parte, há uma maior possibilidade de gerar certos efeitos sociais em outros campos. Incorporar tal interação na análise é interessante em situações em que os grupos estudados abertamente recorrem às narrativas e conceitos antropológicos. Ao ignorar os usos da "cultura" pelos sujeitos objeto de estudo na análise, o antropólogo corre o risco de reificar tal conceito, como se este fosse um dado, e náo uma ferramenta teórica. 
de cultura por populaçóes indígenas, ligado à busca de visibilidade dentro de dinâmicas sociais e políticas ampliadas.

Já que as narrativas antropológicas e as narrativas dos grupos estudados muitas vezes se entrelaçam, há uma responsabilidade por parte do antropólogo (ou de qualquer narrativa acadêmica) de uma reflexão metacognitiva acoplada, carga esta maior se lembrarmos que suas narrativas são tomadas como produtoras legítimas de realidades. Deste esforço metacognitivo emergem conseqüências metodológicas e teóricas de extrema importância.

Em termos metodológicos, a própria relação do antropólogo com os grupos estudados, enquanto "expert em culturas", insere-se dentro de uma dinâmica política em que seu papel frequentemente é usado pelos grupos que estuda como forma de legitimar certas narrativas identitárias. A atuação do antropólogo em campo, na troca que envolve a relação com os grupos estudados - seja escrevendo projetos para financiamento, como foi o meu caso em Peixinhos, seja auxiliando na obtenção de visibilidade para alguma produçáo do grupo ou para o grupo em si, seja escrevendo relatórios e pareceres para o poder judiciário -, não deve se limitar, nas narrativas antropológicas, a aparecer como uma observação sobre as dificuldades do campo nas linhas introdutórias. Isto porque a relação entre o antropólogo e os sujeitos que estuda não é apenas um meio para se chegar a uma análise científica; a relação reflete e é reflexo da imbricação de narrativas que alimentam atuaçóes sociais tanto do antropólogo quanto dos grupos para quem o antropólogo volta o olhar, e portanto, deve fazer parte do estudo em si. Em outras palavras, é justamente na imbricação destas narrativas que se encontrará o que seguir e etnografar, já que a priorização de tal ou qual tipo de construção narrativa revela as conexóes que os próprios sujeitos objeto de estudo realizam. São estas conexôes aquilo a que devemos estar atentos.
Se em Peixinhos as narrativas de pertencimento cultural e de detenção de uma cultura popular genuína são priorizadas pelos moradores, é porque isto garante que os grupos do bairro tenham voz política frente ao Poder Público. Com tal linguagem há uma interlocução com outras instâncias, e tais interlocuçôes - a imbricaçấo de narrativas - carregam em si um especial interesse etnográfico. Assim, através das narrativas se pode perceber como coletivos são formados, isto é, como grupos são formados narrativamente para a açáo, ao contrário de simplesmente serem reflexo de uma voz coletiva pré-existente. As construções narrativas são o veículo através do qual se pode perceber o lócus de agência social, como se verá mais adiante, e a relação entre antropólogo e sujeito objeto de estudo pode ser reveladora disto.

No âmbito teórico, levar a sério as estórias narradas enquanto realidades construídas e, consequentemente, desconstruir as próprias narrativas consagradas na antropologia, contribuem para a discussão contemporânea sobre a crise dos conceitos como cultura e sociedade, e impelem os teóricos a buscar novas ferramentas teóricas. É nesse sentido que tentarei explorar a seguir os escritos de Jerome Bruner em torno das realidades narrativas e seus diálogos implícitos com a antropologia, em especial com o conceito de cultura geertziano, e as possíveis reverberaçōes para a discussão contemporânea acerca dos processos de subjetivaçáo dentro de uma perspectiva antropológica.

\section{Realidades narrativas: a psicologia cultural de Jerome Bruner face à antropologia hermenêutica de Clifford Geertz}

Classificando os psicólogos em "esprit de systèmes" (dogmáticos) e "esprit de finesse" (ágeis 
e adaptáveis), o antropólogo Clifford Geertz (2000) coloca Jerome Bruner entre os segundos. De fato, ao longo de sua carreira, Bruner não fez de seu pensamento um dogma e sim mostrou-se aberto a mudanças: behaviorista na década de 1940 em Harvard, tornou-se um cognitivista no final dos anos 1950, e negou os dois a partir dos anos 1980, propondo o que chamou de "psicologia cultural". Neste movimento metamórfico, ele se inseriu no diálogo da psicologia norte-americana, especificamente uma psicologia que tendeu a se biologizar excessivamente, com seus experimentos laboratoriais e busca por universais humanos - herança do século XIX, de uma concepção que pressupunha que as causas do comportamento humano estavam no substrato biológico (Bruner, 1990).

A sua preocupação em dialogar com esta linha está no fato de ele próprio ter feito parte da chamada Revoluçáo Cognitiva no final dos anos 1950, quando se buscava, depois de um longo período de objetivismo, trazer a "mente" de volta às ciências humanas, em especial as ações mentais: pensar, entender, imaginar, lembrar, sentir, conhecer. Em 1960, juntamente com o psicolingüista George Miller, Bruner fundou o Interdisciplinary Center for Cognitive Research em Harvard, que impulsionou muitos estudos nesta linha (Geertz, 2000).

Não obstante, os frutos da Revolução Cognitiva se mostraram fracionados e tecnicalizados a partir do momento em que a ênfase começou a mudar da construçáo de significado para o processamento de informação. A computação passou a ser a metáfora predominante, e a informaçáo se limitava a ser pensada enquanto mensagem pré-codificada no sistema (Bruner, 1990). Como tal sistema nấo consegue lidar com vaguidão, polissemia ou conexôes metafóricas e conotativas, Bruner acabou se decepcionando com os desdobramentos da Revoluçáo Cognitiva e, em 1990, em um livro entitulado Acts of Meaning, anunciou uma espécie de contra-ataque, uma "revolução cognitiva renovada", a partir de uma abordagem mais interpretativa da cognição, preocupada com o processo de significação.

Assim, a questão do significado, na psicologia cultural que Bruner deseja inaugurar, é colocada no centro da reflexão, mais especificamente, como os processos de construçáo individual de significado se relacionam com os sistemas estabelecidos de significados, crenças, valores e entendimentos compartilhados (Geertz, 2000). Segundo Geertz, a psicologia cultural abre uma série de questôes discutidas em outras disciplinas, como a história, a literatura, o direito, a filosofia, a lingüística e, especialmente, a antropologia; com tantas portas para se abrir e tantas chaves para abri-las, a porta que Bruner escolheu foi a da narrativa. Nas palavras do próprio Bruner:

Creio que o conceito de "significado" (...) reconectou as convençôes lingüísticas com a teia de convençóes que constitui uma cultura. (...) Introduzi o conceito de narrativa por reconhecer o fato evidente de que, para compreender fenômenos culturais, as pessoas não lidam com o mundo evento por evento ou com o texto frase por frase. Elas enquadram eventos e frases em estruturas maiores (...). Estas estruturas maiores proporcionam um contexto interpretativo para os componentes que eles (eventos e frases) comportam. (1990, p. 64, tradução minha)

O que nos interessa aqui é a presença de um paradoxo implícito na argumentação de Bruner. Ao mesmo tempo em que sua análise, inspirada em Mikhail Bakhtin, leva a uma visão de mundo como um campo de diferenças, com a possibilidade de construçôes diferentes da realidade, ele se baseia inteiramente no conceito de cultura de Geertz, que recebeu muitas críticas pelo fato de ressonar o conceito norte-americano clássico vindo de Franz Boas, Margaret 
Mead, Ruth Benedict, ligado a uma noção de visão de mundo e ethos de um grupo particular de pessoas. A idéia que grupos específicos possuem culturas específicas compartilhadas por todos os seus membros leva a uma noção extremamente indiferenciada e homogênea do grupo cultural que desconsidera a existência de diversas formas de diferenças e desigualdades (Ortner, 2005).

Vejamos detidamente como a análise de Bruner concilia os dois. As narrativas possuem, de acordo com Bruner (2001 [1996]), nove características. Três delas se referem à construção de um campo de diferenças: a) a composição hermenêutica da narrativa, isto é, os significados de toda estória são múltiplos; b) a ambigüidade implícita nas narrativas; e c) a negociabilidade inerente das narrativas. A primeira característica implica em uma narrativa nunca comportar uma única interpretação exclusiva. A segunda característica, da ambigüidade contida nas narrativas, é inspirada por Roman Jakobson e seus dois eixos de linguagem. Sendo o eixo vertical o da hierarquia das palavras (país-cidade-bairro-quadra-rua), e o eixo horizontal o da localização de uma palavra e seu papel em uma frase ou contexto (faca-garfo-prato-copovinho-conversa), seria o segundo aquele que abre a possibilidade de haver ambigüidade na palavra, dependendo com quais outras palavras aquela se relaciona. Essa ambigüidade é caracterizada pela já mencionada "subjuntivização da realidade", ou seja, quanto mais incerto, mais aberto a interpretaçóes. A terceira característica, a da contestabilidade essencial das estórias, é o que permite se aceitar facilmente versões concorrentes de estórias com certa cautela perspectiva, muito mais que argumentos ou provas. Para Bruner, esta prontidão a considerar diversas interpretaçôes confere a flexibilidade necessária para a coerência da vida cultural.

Ora, se por um lado haveria espaço para toda a heterogeneidade, para toda a possibilidade de contemplar a diversidade de interpretações, por outro lado, a realidade narrativa também seria caracterizada por certos padrôes: d) a existência de uma versáo canônica nas narrativas; e, e) a extensibilidade histórica da narrativa. A realidade narrativa, segundo o psicólogo, nos ligaria ao que é considerado canônico - esperado e legítimo. Os cânones servem como uma forma de contexto em torno do qual impomos coerência sobre o passado, transformando-o em história, cujo acúmulo constitui um empreendimento narrativo. Segundo Bruner, é a sensação de se fazer parte de um "passado canônico" que permite que estruturemos nossos auto-relatos.

Há duas filiaçóes implícitas em sua argumentação. A primeira, que enfatiza a diferença e a heterogeneidade, é dada pela influência de Bakhtin e seu sócio-construtivismo. Segundo

5. As outras quatro características da construção narrativa são, em primeiro lugar, a temporalidade na estrutura narrativa, que é aquela "humanamente relevante". Já muito consolidada na tradição antropológica é a tentativa de apreender temporalidades diferentes, portanto, o "humanamente relevante" se refere à relevância temporal de açóes dentro de determinados contextos e a partir de específicas visóes de mundo. Em segundo lugar, a particularidade genérica que marca a narrati$v a$, ou seja, as histórias particulares são interpretadas como se enquadrassem em gêneros ou tipos. Os gêneros são formas de enquadrar certos textos e auxiliar na extração de sentido do mesmo, são "formas culturalmente especializadas de vislumbrar a condição humana e de comunicá-la” (Bruner, 2001 [1996], p. 131). É o gênero que dá à realidade a sua forma, e não o contrário. Outra marca da construção narrativa é a da centralidade do problema: as histórias giram em torno de problemas, normas violadas, dilemas. Os tipos de dilema também diferem dependendo do contexto dentro do qual essas narrativas são produzidas. A última característica é o fato de as açôes narrativas implicarem estados intencionais, motivados por crenças, desejos, teorias e valores. Isto implica em uma agência, ou seja, um certo elemento de liberdade está sempre implícito na narrativa (Bruner, 2001 [1996]). Tal aspecto é importante para a nossa discussão seguinte, acerca da antropologia da subjetividade. 
Bakhtin (2004 [1929]), a linguagem não deve ser pensada como abstraçáo, mas fato socialhistórico. Ele se coloca, portanto, contra a lingüística estruturalista de Saussure que abstrai o contexto social para uma análise da linguagem como sistema abstrato. A idéia estruturalista de signo enquanto composto de significante e seu correspondente significado ignora a presença do usuário da língua, o que para Bakhtin é essencial para se entender a atribuição de significados aos significantes. Para este autor, a atribuiçáo de significados se dá sempre em processo, os signos estão sempre em significação a partir do contexto e dos seus usos. Dessa maneira, a preocupação de Bruner e da psicologia cultural em torno dos significados pressupóe a idéia de significação enquanto processo dialógico, e não abstraído de seu contexto.

A segunda filiação é ao conceito de cultura do antropólogo Clifford Geertz. O próprio livro Acts of Meaning foi fruto de uma série de palestras efetuadas em 1989 e 1990 denominada "Jerusalem-Harvard Lecturers", em que os palestrantes eram justamente Clifford Geertz em antropologia e Jerome Bruner em psicologia. Argumentando sobre a necessidade de colocar como questáo central na psicologia o significado e os processos pelos quais os significados são criados e negociados numa comunidade através da já mencionada psicologia cultural, Bruner parte de um conceito de sistemas simbólicos e cultura que segue a tradição $\mathrm{da}$ antropologia interpretativa inaugurada por Geertz. Segundo Bruner (1990), a psicologia está profundamente imersa na cultura, devendo, portanto, organizar-se em torno de processos de significação que conectam o ser humano à mesma.

O conceito de cultura que Geertz propóe em 1973, no seu célebre Interpretação das Culturas é o de sistemas entrelaçados de signos interpretáveis, uma espécie de contexto, algo dentro do qual eles podem ser descritos de forma inteligível - isto é, descritos com densidade (Geertz, 1989 [1973], p. 10).

Este conceito carrega consigo algumas premissas. A primeira, também presente em Bruner, é a busca de uma ciência que não seja uma ciência experimental à procura de leis, mas sim de uma "ciência interpretativa à procura do significado" (p. 4). A segunda é a de que a realidade social é como um texto, "um manuscrito estranho, desbotado, cheio de elipses, incoerências, emendas suspeitas e comentários tendenciosos (...)” (p. 7). Fazer etnografia seria, portanto, ler este manuscrito, construir uma leitura dele através de uma descrição densa de uma "hierarquia estratificada de estruturas significantes em termos das quais gestos são produzidos, percebidos e interpretados" (p. 5).

A terceira, e aqui Geertz é inspirado por Wittgenstein, a cultura é pública e à medida que mergulhamos mais intensamente numa cultura estranha, as pessoas se tornam "transparentes para nós”. Ao primeiro contato, a falta de compreensão do povo que se estuda se dá pela dificuldade de se situar entre eles. A pesquisa etnográfica é justamente a experiência pessoal de nos situarmos, com o fim não de falar, mas "conversar com eles" (p. 10). A abordagem semiótica da cultura auxilia o antropólogo a ganhar acesso ao mundo conceitual no qual vivem os sujeitos para que possa conversar com eles e torná-los acessíveis.

Apesar de Geertz partir de uma perspectiva semiótica para elaborar seu conceito de cultura e análise antropológica, a porta que tentava abrir náo era, como a de Bruner, a da narrativa, e talvez por isso o antropólogo não se estenda tanto quanto o psicólogo nas ambigüidades inerentes a qualquer interpretaçáo. Vale lembrar que mesmo quando Geertz aborda a questão da contestabilidade das interpretaçôes, ao afirmar que 
comprometer-se com um conceito semiótico de cultura e uma abordagem interpretativa é comprometer-se com uma visão afirmativa da etnografia como "essencialmente contestável" (Geertz, 1989 [1973], p. 20)

Ele se limita às interpretaçóes feitas pelos antropólogos e não às diferentes interpretaçôes dentro do próprio grupo estudado. A dedução de que existe uma interpretação nativa, e que o antropólogo realiza uma interpretação de segunda ou terceira máo a partir dela, leva a uma falta de visão política do ato de interpretar a realidade social, algo pelo qual o autor é frequentemente acusado (Almeida; Rebouças; Silva, 1993; Kuper, 2002). Ao afirmar como característica inerente da narrativa a ambigüidade e sua composição hermenêutica, Bruner abre a possibilidade de uma visão mais heterogênea de grupos que compartilham narrativas do que estava implícito no trabalho de Geertz.

Seria injusto dizer que Geertz alguma vez tenha afirmado a homogeneidade do grupo nativo. Ao contrário, ao comentar a obra de Bruner, esclarece: "Se há algo com o qual a antropologia é obcecada, é em quanta diferença a diferença faz" (Geertz, 2000, p. 197, tradução minha). No entanto, quando afirma que a interpretação antropológica deve traçar a curva de um discurso social, mesmo que seja feito por diversos idiomas, e fixá-lo em uma forma inspecionável, e que "uma boa interpretação de qualquer coisa nos leva ao cerne do que propomos interpretar" (Geertz, 1989 [1973], p. 13, grifos meus), deixa implícita uma noção de leitura de texto em que a interpretação está no próprio texto e o leitor participa apenas desvendando a interpretaçấo "inerente" a ele, como se apenas uma estivesse contida no mesmo. O que resulta disso é uma visão demasiadamente homogênea dos significados inerentes à realidade social, sem muita atenção aos conflitos de significados que advêm da heterogeneidade social.

Bruner, ao contrário, reconhece a heterogeneidade, mas não abre mão do conceito de cultura que compartilha com Geertz, e a saída para as divergências de interpretação se dá justamente numa das características mais importantes das narrativas: a da canonicidade. Para o psicólogo:

(...) a viabilidade de uma cultura se encontra essencialmente em sua capacidade de resolver conflitos, de explicar diferenças e renegociar significados comunais. Os "significados negociados" (...) se tornam possíveis pelo aparato da narrativa de lidar simultaneamente com o canônico e o excepcional. Portanto, se uma cultura deve conter normas, deve também conter um conjunto de procedimentos interpretativos que permitam um afastamento daquelas normas significativas em termos de padróes estabelecidos de crenças. (Bruner, 1990, p. 47, tradução minha)

O ordinário, comum, é vivido como canônico, como normas esperadas para falar e agir em certas situaçôes, e a ação é interpretada como apropriada ou não pelo contexto, o lócus da ação em questão. A exceção deve ser interpretada tendo em vista o elemento canônico violado e um estado intencional. Quando Bruner afirma, justificando porque a narrativa seria a ferramenta apropriada para a psicologia cultural, que

Ela [a narrativa] lida (...) com o material da açáo humana e da intencionalidade humana. Ela media o mundo canônico da cultura e o mundo mais idiossincrático de crenças, desejos e expectativas. (Bruner, 1990, p. 52, tradução minha)

Fica claro que o que denomina não-canônico se refere ao mundo "interno", aos estados intencionais, e o canônico ao "externo", à cultura. 
Lendo Bruner à luz de Geertz, a impressão que se tem é a da divisão de tarefas do antropólogo realizando uma descrição densa, interpretativa, de uma cultura específica, e a do psicólogo fazendo a conexão entre a intencionalidade que envolve crenças e desejos e o mundo cultural, externo.

A discussáo que Bruner empreende sobre a relação entre o mundo cultural (canônico) e o mundo idiossincrático (estados intencionais) é extremamente interessante e já antiga também na antropologia. Não farei aqui, no entanto, uma discussão de como tal relação se apresentou na disciplina ao longo do tempo, apenas introduzirei brevemente algumas das idéias recentes de Sherry Ortner, que procura justamente relacionar elementos culturais e estados internos na busca por uma antropologia da subjetividade. À luz de suas idéias, sugiro caminhos baseados no conceito de cultura de Homi Bhabha.

\section{Antropologia da subjetividade}

Assim como Bruner, alguns trabalhos na antropologia têm se movido entre o exame de elementos culturais e os estados internos dos sujeitos atuantes. ${ }^{6}$ Sherry Ortner (2005), em um artigo em que defende a importância na antropologia da questáo da subjetividade, definida como modos de percepção, afeto, pensamento e desejo, afirma que a dimensão da subjetividade já estava presente na obra de Geertz. Apesar de reconhecer as razões à crítica ao conceito de cultura de Geertz, e nos perigos que o conceito traz como forma de essencializar grupos inteiros de pessoas, também defende o conceito, desde que reformulado de maneira a lhe conferir um valor político.

Para Ortner, uma formação cultural seria um corpo relativamente coerente de símbolos e

6. Segunda a autora, alguns dos antropólogos que exploram construçôes subjetivas da condição de sujeição são Lila Abu-Lughod, Jose Limón, Ashis Nandy e Tassadit Yacine. significados, ethos e visão de mundo, corpo este não consensuado, mas ideológico e parte das forças e processos de dominação. A figura mais importante para a reformulação do conceito de cultura, segundo a autora, foi Raymond Williams, em Marxism and Literature de 1977, com sua mistura da noção de cultura à idéia gramsciana de hegemonia, para tentar entender as formaçóes produzidas pela cultura nas subjetividades (estruturas de sentimento), em contextos históricos específicos de poder, desigualdade e mercantilização (Ortner, 2005).

Em alguns momentos, Ortner se aproxima muito da proposta de Bruner, mas de modo invertido. Este, na psicologia, esforça-se por considerar o contexto (sistemas simbólicos) na construçáo de significado, e aquela, na antropologia, defende a inserção da questão da subjetividade na consideraçáo sobre os sistemas simbólicos mais amplos. A autora procura mostrar que a importância de reinstalar a questấo da subjetividade na teoria social é política, uma vez que esta é central para se pensar em "agência”, que adota a forma de desejos e intençōes específicos dentro de uma matriz de subjetividade, de sentimentos, pensamentos e significados culturalmente constituídos. Aí estaria, de acordo com Ortner, a grande contribuição da teoria de cultura de Geertz: baseado na teoria filosófica literária do processo cultural e inspirado em Wittgenstein, ele insiste na construção das subjetividades através de processos simbólicos imersos no mundo social. Assim como Weber pensa a influência do protestantismo na configuração da consciência dos primeiros sujeitos modernos (uma estrutura particular de sentimentos), o balinês vê na briga de galos um "modelo de" (ordena-lhe significados particulares) e um "modelo para", numa espécie de educação sentimental (processo pedagógico). A participação na rinha daria ao homem acesso à sua própria subjetividade (Ortner, 2005, tradução minha). 
É interessante pensar na classificação que Ortner faz das três linhas de discussão da teoria social e cultural hoje. A primeira seria o pós-estruturalismo, que denuncia qualquer totalização classificatória como forma de dominaçấo. Entre as feministas como Joan Scott, qualquer idéia de "Homem" no sentido universal se referiria na verdade ao gênero masculino. Entre os autores pós-coloniais, como Gayatri Spivak, tal totalização se referiria a um projeto especificamente ocidental de dominação de homens colonialistas brancos. Para a autora, esta linha seria marcada por um antihumanismo que traria problemas para uma antropologia que queira entender não só funcionamento do poder, mas "as intençôes dos subalternos (no sentido gramsciano) de alcançar o privilégio de converterem-se em sujeitos" (Ortner, 2005, p. 27).

A segunda linha, à qual a autora se filia, é denominada por ela de "pós-levi-straussiana" (não pós-estruturalista), que tentaria colocar o sujeito agente no centro da teoria social, também de uma maneira que não reabilitasse o ilusório universalismo do "Homem". Esta corrente é geralmente ligada à chamada teoria da prática, que inclui Pierre Bourdieu, Anthony Giddens e Marshall Sahlins. Se as obras destes autores são inspiração para Ortner, esta reconhece que há neles uma falta: justamente a questão da subjetividade, isto é, a concepçâo do sujeito como um ser existencialmente complexo que sente, pensa, reflete, dá e busca sentido.

A terceira e última linha é a da tradição investigativa e interpretativa em um plano cultural mais geral, que investiga o papel de "formaçôes culturais" específicas na configuraçãa e geração das subjetividades, segundo ela, linha da qual Geertz faria parte. O que a autora pretende é justamente acrescentar à linha pós-levi-straussiana as questóes de subjetividade, para ela já presentes na antropologia de Geertz, desde que seu conceito de cultura seja politizado.
Pode-se identificar em Ortner duas principais preocupaçóes: a da importância da questão da subjetividade para a antropologia e a da reformulação do conceito de cultura. É nesse sentido que ela parece querer conciliar as duas últimas linhas, na busca por uma

antropologia da subjetividade que pense a configuração cultural das subjetividades considerando as relaçôes sociais de poder, assim como as complexidades das subjetividades pessoais dentro de um mundo desigual (Ortner, 2005, p. 47, tradução minha).

Este tipo de tentativa é muito interessante em um lugar como Peixinhos, marcado pela sensação de marginalidade, opressão e profundas desigualdades sociais. Mas aqui um complicador se coloca. Já vimos que a busca de Ortner pela configuração cultural da subjetividade implica na politização do conceito de cultura geertziano através do acréscimo da noção de hegemonia gramsciana, assim como desenvolvida por Raymond Williams (1977). A incorporação da dimensão política é de fato muito interessante. No entanto, é preciso muita atenção, ao se partir de tal perspectiva, para não encampar a idéia de cultura e de grupos enquanto totalidades. Isto porque pensar na interação entre grupos, em uma luta pela conquista de hegemonia em certa configuração política, pauta-se pela idéia de formaçôes culturais dentro de grupos. O risco é o de que surjam demasiados vestígios das mônadas culturais.

Evitar tais mônadas talvez seja uma simples questão de ênfase. Ao invés de explorar a configuração cultural da subjetividade considerando relaçóes de poder, talvez se devesse voltar o olhar para como as relaçôes de poder, juntamente com modos de percepção, afeto, pensamento e desejo, configuram certas construçóes narrativas canônicas ("a cultura"). Para entender melhor essa mudança de ênfase, poderíamos deixar por um 
instante o conceito de cultura geertziano (politizado ou não) de lado, trazer Homi Bhabha à discussão, e voltar a Peixinhos.

Se partirmos de Bhabha e de sua noção de que a comunidade em Peixinhos não é "comunidade" por ser marcada por características essenciais, dadas a priori, mas pela construçáo de narrativas do passado e de pertencimento cultural, e se, como vimos em Peixinhos, essas construçóes estão ligadas a uma dimensão política das dinâmicas sociais nas quais seus moradores estão inseridos, podemos então explorar um conceito de cultura que seja também construção narrativa, um produto da configuração política e não um ente que pré-existe à mesma. Ora, a questão que se coloca, portanto, não é como a cultura molda a subjetividade, como quer Ortner, mas como dinâmicas sócio-políticas, aliadas a subjetividades sempre em construção, nunca acabadas, incitam a enunciação de narrativas de pertencimento que, por sua vez, engendram subjetividades deslocadas (mas não descoladas) daquelas imediatamente anteriores, num processo sempre contínuo. ${ }^{7}$ Talvez fosse necessário, nesse sentido, pensar não na configuração cultural da subjetividade, mas na configuração política da subjetividade, ou entáo na configuração cultural da subjetividade baseada no conceito da cultura de Bhabha: uma cultura como construção, que seja híbrida, produtiva, dinâmica, aberta, em constante transformação; "não mais um substantivo, mas um verbo" (Menezes de Souza, 2004 , p. 125 , grifo no original).

Tanto a subjetividade quanto a cultura são formadas na constante dialogia. Bruner (1990), ao explorar a questáo da subjetividade, afirma que esta é o resultado do processo de significação, não enquanto núcleos isolados

7. Mesmo subjetividades que se afirmam e reafirmam constantes através do tempo necessitam continuamente reiterar enunciativamente tal similitude temporal. Cada enunciaçáo, mesmo que repetindo a anterior, é sempre um deslocamento desta última. de consciência dentro das mentes individuais, mas distribuídos interpessoalmente. $\mathrm{E}$ a subjetividade é construída interpessoalmente porque está sempre em construção dialógica, assim como a cultura. O espaço dialógico é o que Bhabha denomina de terceiro espaço, em que as diferenças são pensadas enquanto aproximaçóes e justaposiçóes que nos posicionariam sempre na fronteiras entre a diferença e a mudança (Bhabha, 2003, p. 178). Para o autor, este processo de constante mudança se materializa através das narrativas comuns do passado que criam uma teia de estórias e, aí sim, configuram os que compartilham tais narrativas enquanto grupos, comunidades, mudando a direçáo do próprio fluxo de suas açôes. É desse modo que devemos pensar a luta política em Peixinhos não como resultado da interação de diferentes grupos pré-existentes, mas sim como produtora dos grupos enquanto construçóes narrativas daquele contexto político. A partir desta idéia, podemos explorar como configuraçóes políticas e subjetividades abertas, em construção, conjugam-se e orientam a construção de certas narrativas, que por sua vez redirecionam a subjetividade de Zuleide, dos participantes da luta contra o lixo, dos integrantes do movimento Boca do Lixo e dos usuários do Nascedouro.

A agência social, a subjetividade e o sentimento de pertencimento a um grupo (comunidade ou cultura no sentido defendido por Bhabha), portanto, estáo ligados ao "direito de narrar" dos chamados subalternos. Suas narrativas, construídas a partir de "arquivos fragmentados e disjuntos", moldam as subjetividades e constituem "formas de agência que são coletivas e afetivas" (Bennet; Bhabha, 1990, p. 39).

A noção de agências afetivas e coletivas abarca as três dimensóes - a agência social, a subjetividade e o pertencimento cultural - que devem ser analisadas em conjunto com dinâmicas sociais e políticas. Se nossas narrativas constroem 
nossa(s) subjetividade(s) e estas dependem do interlocutor, percebemos que fazemos parte de múltiplas comunidades, cada qual mergulhada em sua rede de relaçóes e de narrativas de um passado comum de experiências e memórias. Contextos sócio-políticos distintos incitam a produção de diferentes realidades narrativas e de subjetividades em constante redirecionamento. Da mesma forma, realidades narrativas e subjetividades deslocadas têm o poder de redirecionar os próprios contextos sócio-políticos, num movimento contínuo de deslocamento mútuo.

O que defendo aqui, dessa maneira, é que uma antropologia que busque investigar a questão da subjetividade deve dar atenção às narrativas de passado e pertencimento cultural em relação às dinâmicas sociais e políticas nas quais as autoconstruídas comunidades estão inseridas (e as quais transformam), e não em relação a alguma cultura pré-existente. Insistir no solo movediço do conceito de cultura, enquanto sistemas simbólicos compartilhados, num contexto em que as narrativas de pertencimento cultural - as narrativas antropologizadas - imbricam-se com narrativas antropológicas, impede-nos de exercer nossa sensibilidade metacognitiva.

Tal sensibilidade é necessária para percebermos que a reformulaçáo de nossas ferramentas teóricas deve ir além de estabelecer um conceito de cultura que se diz "político". Isto porque apesar da importância desta perspectiva, nela o lócus da agência social é sempre a subjetividade, configurada a partir de uma matriz cultural e relaçôes de poder fixadas de antemáo. $\mathrm{O}$ deslocamento das próprias relaçóes de poder é, portanto, projeto de futuro, sempre inalcançável.

A agência social da comunidade de Peixinhos - comunidade por compartilhar realidades narrativas do passado - carrega outra politicidade, não como projeto de futuro, mas como ação no presente, já que sua prática de narrar, constituindo cultura e subjetividade sempre em mutação, permite-lhe agir no jogo político do agora. Nesse sentido, o contínuo deslocamento das subjetividades (de Zuleide, Maria Gadelha, senhor Biu da Procissão, dona Duda, dona Ester, seu Efigênio, senhor Caetano e Oriosvaldo) e das configuraçóes políticas (a luta dos moradores de Peixinhos contra o lixo, os governos municipal e estadual, o Boca do Lixo, o Matadouro e o Nascedouro) se dá a partir da prática narrativa - o lócus da agência social. Para arriscar uma descrição desta dinâmica sempre aberta e em mutação, talvez devêssemos começar por rascunhar aquilo que, de forma bastante perspicaz, Charles Taylor (2003), em um diálogo com Homi Bhabha, chamou de "narrativas densas".

\section{In search of thick narratives: issues around narrative realities, subjectivity and social agency}

abstract Having as background the fieldwork experience in the neighborhood of Peixinhos in Olinda, the present article discusses the importance of considering in anthropological analyses narratives of daily-life events, identity and the past, as well as the realities created by them. The article discusses psychologist Jerome Bruner's approach on "narrative realities" and his dialogue with anthropology, in particular with the geertzian concept of culture and with the current discussion around the importance of including in anthropological writings reflections about subjectivity processes. The aim here is to reflect critically upon the range and limitations of Geertz's culture theory and, as an alternative, to point out some of Homi Bhabha's ideas on social agency, subjectivity and cultural belonging, from a perspective that takes into account the social and political dynamics that influence and define groups as such.

keywords Narrative realities. Anthropology of subjectivity. Social agency. Jerome Bruner. 


\section{Referências bibliográficas}

ALMEIDA, Heloísa Buarque de; REBOUÇAS, Lídia Marcelino; SILVA, Vagner Gonçalves da. Entrevista com George Marcus. Cadernos de Campo, São Paulo: PPGAS/USP, n. 3, p. 132-139, 1993.

BAKHTIN, Mikhail. Marxismo e filosofia da linguagem. Sáo Paulo: Hucitec, 2004 [1929]. 196 p.

BENNET, David; BHABHA, Homi. Liberalism and minority culture: reflections on "Culture's in between”. In: BENNET, David (Org.). Multicultural states: rethinking difference and identity. London: Routledge, 1998, p. 37-46.

BHABHA, Homi. Culture's in Between. In: BENNET, David (Org.). Multicultural states: rethinking difference and identity. London: Routledge, 1998, p. 29-35 On Writing Rights. In: GIBNEY, M. (Org.).

Globalizing rights: the Oxford Amnesty lectures. Oxford: Oxford University Press, 2003, p. 162-182.

BOURDIEU, Pierre. Homo academicus. Paris: Les Éditions de Minuit, 1984. 302 p.

BRUNER, Jerome. Actual minds, possible worlds. Cambridge: Harvard University Press, 1986. 202 p. Acts of meaning. Cambridge: Harvard University Press, $1990.180 \mathrm{p}$.

A cultura da educação. Porto Alegre: Artmed, 2001 [1996]. 186 p.

FIORIN, José Luiz. Bakhtin e a concepção dialógica da linguagem. In: ABDALA JÚNIOR, Benjamin (Org.). Margens da cultura: mestiçagem, hibridismo e outras misturas. São Paulo: Boitempo, 2004. p. 37-66.

GEERTZ, Clifford. A interpretação das culturas. Rio de Janeiro: LTC, 1989 [1973]. 214 p.

Available light: anthropological reflections on philosophical topics. Princeton: Princeton University Press, 2000. 272 p.

ISER, Wolfgang. The Act of Reading: a theory of aesthetic response. London: Routledge \& Kegan Paul, 1978. 239 p.

KUPER, Adam. Cultura, diferença, identidade. In: Cultura: a visão dos antropólogos. Bauru: EDUSC, 2002. 332 p.
LEACH, Edmund. Sistemas politicos da Alta Birmânia. São Paulo: Edusp, 1996 [1954]. 374 p.

MENEZES DE SOUZA, Lynn Mario. Hibridismo e tradução cultural em Bhabha. In: ABDALA JÚNIOR, Benjamin. (Org.). Margens da cultura: mestiçagem, hibridismo e outras misturas. São Paulo: Boitempo, 2004, p. 113-133.

ORTNER, Sherry. Geertz, subjetividad y conciencia posmoderna. Etnografias contemporâneas. Buenos Aires: Universidad Nacional de San Martin, ano 1, n. 1, p. 25-54, 2005.

PAULA, Zuleide de. Peixinhos: um rio por onde navegam um povo e suas histórias. Olinda: Ediçóes Bagaço e Centro de Cultura Luiz Freire, 1999. 130 p.

TAYLOR, Charles. Response to Bhabha. In: GIBNEY, M. (Org.), Globalizing rights: the Oxford Amnesty lectures 1999. Oxford: Oxford University Press, 2003, p. 184187.

WILLIAMS, Raymond. Marxism and Literature. Oxford: Oxford University Press, 1977. 110 p.

\section{Agradecimentos}

Este artigo foi escrito como trabalho final do curso "Identidade e Narrativas", ministrado pelo prof. dr. Lynn Mario T. Menezes de Souza e oferecido pelo Departamento de Letras Modernas da Universidade de São Paulo no segundo semestre de 2005. Agradeço a Lynn Mario pelas instigantes aulas, e a meu orientador, o prof. dr. Júlio Assis Simóes, pelas sugestôes e comentários. Agradeço também às colegas Nadja Marin e Vivian Schoereder pelas revisóes textuais. As falhas remanescentes são de minha inteira responsabilidade.

\section{autor Anna Catarina Morawska-Vianna \\ Doutoranda em Ciência Social (Antropologia Social)/USP}

Recebido em 15/02/2006

Aceito para publicação em 30/09/2007 